\title{
Light and electron microscopical observations of the effects of high-density lipoprotein on growth of Plasmodium falciparum in vitro
}

\author{
H. IMRIE ${ }^{1 *}$, D. J. P. FERGUSON ${ }^{2}$, M. CARTER ${ }^{1}$, J. DRAIN ${ }^{3}$, A. SCHIFLETT $^{4}$, \\ S. L. HAJDUK ${ }^{4}$ and K. P. DAY ${ }^{1}$ \\ ${ }^{1}$ Peter Medawar Building for Pathogen Research and Department of Zoology, University of Oxford, Oxford OX1 3SY, UK \\ ${ }^{2}$ Department of Pathology and Bacteriology, Fohn Radcliffe Hospital, Oxford OX39DU, UK \\ ${ }^{3}$ Department of Biochemistry and Molecular Genetics, School of Medicine, University of Alabama at Birmingham, \\ Birmingham AL, 35294, USA \\ ${ }^{4}$ Marine Biological Laboratory, Woods Hole, MA 02543, USA
}

(Received 10 September 2003; revised 27 November 2003; accepted 27 November 2003)

\section{SUMMARY}

Human serum high-density lipoprotein (HDL) is necessary and sufficient for the short-term maintenance of Plasmodium falciparum in in vitro culture. However, at high concentrations it is toxic to the parasite. A heat-labile component is apparently responsible for the stage-specific toxicity to parasites within infected erythrocytes $12-42 \mathrm{~h}$ after invasion, i.e. during trophozoite maturation. The effects of HDL on parasite metabolism (as determined by nucleic acid synthesis) are evident at about $30 \mathrm{~h}$ after invasion. Parasites treated with HDL show gross abnormalities by light and electron microscopy.

Key words: Plasmodium falciparum, high density lipoprotein.

\section{INTRODUCTION}

Plasmodium falciparum is the most pathogenic species causing human malaria. Erythrocytes become infected following attachment and invasion by merozoites. Various phases of parasite development can be observed during the 48 -h erythrocytic cycle (Freeman \& Holder, 1983) i.e. rings (1-20 h); trophozoites (21-32 h); schizonts (33-48 h). Schizont rupture results in the release of daughter merozoites infective for erythrocytes. As many as 32 daughter merozoites can be produced within the schizont (Kwiatkowski \& Nowak, 1991). However, the efficiency of replication may be determined by the environment within the circulation and at sites of sequestration of infected erythrocytes. Mediators of the innate and acquired immune system, fever, competition for erythrocytes of the optimum maturity as well as physical parameters related to the invasion of erythrocytes in the circulation, may all affect the efficiency of parasite replication and re-invasion (Bruce \& Day, 2000).

It is possible to investigate the erythrocytic cycle in an in vitro culture system developed by Trager \& Jensen (1976). In this culture system the parasite

* Corresponding author: Peter Medawar Building for Pathogen Research and Department of Zoology, University of Oxford, Oxford OX1 3SY, UK. Tel: +01865 271247. Fax: +01865 281898. E-mail: heather. imrie@ceid.ox.ac.uk grows in $5-10 \%$ human serum in an atmosphere of low oxygen tension. During adaptation of new isolates of $P$. falciparum to in vitro culture, not all non-immune human sera allow adequate replication of the parasite and occasionally lethal batches of sera have been identified (K. P. Day, unpublished observations).

$P$. falciparum cultured in vitro has a requirement for HDL within the growth medium, although it has been reported that $\mathrm{HDL}$ can be toxic at high concentrations (Grellier et al. 1991). Here we report on our own findings into the effects of HDL on $P$. falciparum in vitro.

\section{MATERIALS AND METHODS}

\section{HDL purification}

The HDL fraction of human serum was prepared by ultracentrifugation and dialysis against phosphatebuffered saline containing $0.3 \mathrm{~mm}$ EDTA (PBS-E), according to the method of Hajduk et al. (1989). Freshly collected human blood was used to prepare $200 \mathrm{ml}$ of serum. Intact serum was adjusted to a density of $1.063 \mathrm{~g} / \mathrm{ml}$ with sodium bromide and low density lipoprotein and chylomicrons (density $\leqslant 1.063 \mathrm{~g} / \mathrm{ml}$ ) were removed by flotation. The HDL and protein-rich fraction was adjusted to $1 \cdot 26 \mathrm{~g} / \mathrm{ml}$ with sodium bromide and following ultracentrifugation, the fractions of density $\leqslant 1 \cdot 26 \mathrm{~g} / \mathrm{ml}$ (HDL2, HDL 3 and VHDL) and of density $>1 \cdot 26 \mathrm{~g} / \mathrm{ml}$ (i.e. the majority of non-lipid plasma proteins) were 
collected. The HDL, LDL and protein-rich fractions were dialysed and concentrated and their protein content was determined by spectrophotometry and equalized in each by addition of PBS-E as necessary. HDL, LDL and protein-rich fractions were heattreated by maintenance at various temperatures $(0$, 37 and $50^{\circ} \mathrm{C}$ ) for $45 \mathrm{~min}$.

\section{P. falciparum cultivation and growth inhibition assay}

Isolates and cloned lines of $P$. falciparum were cultured according to the method of Trager \& Jensen (1976) as modified by Day et al. (1993) at 5\% haematocrit. The parasites were synchronized by 'plasma gel' selection (Pasvol et al. 1978) in one cycle and sorbitol treatment (Lambros \& Vanderburg, 1979) in the next cycle. These sorbitol-treated, ring-stage parasites were used to set up $250 \mu \mathrm{l}$ cultures at $1 \%$ parasitaemia in 24-well plates (unless otherwise stated). When cultures were at the mid to late ring stage (12-18 h post-invasion), the parasites were transferred to RPMI 1640 medium (without serum) and HDL, LDL, protein-rich fractions or equivalent volumes of PBS-E were added to the complete medium to give final concentrations of $0-4 \mathrm{mg} / \mathrm{ml}$ of protein. The experiment was performed in triplicate. The maximum test volume added was variable according to batches of HDL but never exceeded $16 \mu 1$. Media were replaced every $24 \mathrm{~h}$ with fresh aliquots of RPMI 1640 containing HDL etc. Parasitaemia was assessed following parasite re-invasion, $60 \mathrm{~h}$ after addition of HDL; infected erythrocytes were labelled with ethidium bromide, cultures were then fixed with $0.5 \%$ paraformaldehyde and parasitaemia determined using flow cytometry (Piper, Roberts \& Day, 1999). This experiment allowed assessment of the ability of the different fractions to support parasite growth. In similar experiments the toxic effect of HDL in the presence of human serum was investigated; synchronous $12-18 \mathrm{~h}$ parasites were cultured in complete medium (RPMI 1640 medium supplemented with $5 \%$ human serum, previously screened to support parasite growth) with additional HDL, LDL or protein-rich fraction. After $24 \mathrm{~h}$ the medium was removed and replaced with fresh complete medium which did not contain HDL etc. These experiments were performed with 8 different preparations of HDL taken from different individuals. Nucleic acid synthesis during trophozoite maturation was assessed by measurement of ${ }^{3} \mathrm{H}$ hypoxanthine uptake by parasite cultures (Desjardins et al. 1979) using the 'Filtermate' cell harvester and 'Topcount NXT' scintillation counter (PerkinElmer). This experiment was performed in duplicate using three different preparations of HDL. Visual determination of parasite health was made at various time-points following addition of HDL using both light microscopy of Giemsa-stained cells and electron microscopy.
Light and electron microscopy of infected erythrocytes

Cultures of $P$. falciparum infected erythrocytes in complete medium were divided into aliquots at the late ring stage (12-18 h after invasion) and treated with HDL (1.44 mg of protein/ml) or an equivalent volume of PBS-E (control). The cultures were maintained for $30 \mathrm{~h}$, the HDL being removed with the culture supernatant and replaced with fresh complete medium. Thin smears were prepared at various time-points, fixed with methanol and stained with Giemsa's stain. The samples for electron microscopy were prepared $24 \mathrm{~h}$ after addition of HDL $(2.5 \mathrm{mg}$ of protein $/ \mathrm{ml})$. The samples were fixed in $2.5 \%$ glutaraldehyde in $0.1 \mathrm{M}$ cacodylate buffer. The cells were post-fixed in $1 \%$ osmium tetroxide, dehydrated in ethanol, treated with propylene oxide and embedded in Spurr's epoxy resin. Thin sections were stained with uranyl acetate and lead citrate prior to examination in the JEOL $1200 \mathrm{EX}$ transmission electron microscope. For quantification, a random sample of 100 infected erythrocytes was examined and placed into 1 of 3 groups; early stages which comprised rings up to early trophozoites; late stages comprising mid-trophozoites to mature schizonts and dead parasites exhibiting features consistent with irreversible degeneration (loss of membrane and organellar integrity). This was repeated a minimum of 4 times for separate blocks from each sample.

\section{RESULTS}

Varying amounts of HDL, LDL or protein-rich fractions were added to $P$. falciparum ring-stage cultures (12-18 h post-invasion) in the absence of whole human serum. The culture medium was replaced every $24 \mathrm{~h}$ with fresh RPMI and ultracentrifugation fractions and, after $72 \mathrm{~h}$, the parasitaemia in each culture was determined. HDL at a concentration of $0.75 \mathrm{mg} / \mathrm{ml}$ supported growth of parasites in the absence of whole serum, whereas at a concentration of $3 \mathrm{mg} / \mathrm{ml}$ there were virtually no normal parasites, as assessed by light microscopy. LDL at equivalent protein concentration did not support parasite growth in the absence of serum and the protein-rich fraction of serum supported some growth at high concentration (Fig. 1A). Slight batch variation in the toxicity was evident with different HDL preparations (data not shown).

In order to determine whether the HDL toxicity was evident in the presence of normal human serum, various concentrations of HDL were added to ringstage cultures (12-18 h post-invasion) in medium containing 5\% human serum and then removed from the cultures after $24 \mathrm{~h}$, at mid-schizont stage (36-42 $\mathrm{h}$ post-invasion). Thereafter cultures were maintained with $5 \%$ serum (without HDL) until reinvasion had occurred. Fig. 1B shows a doseresponse curve where HDL containing $2 \cdot 4 \mathrm{mg} / \mathrm{ml}$ 

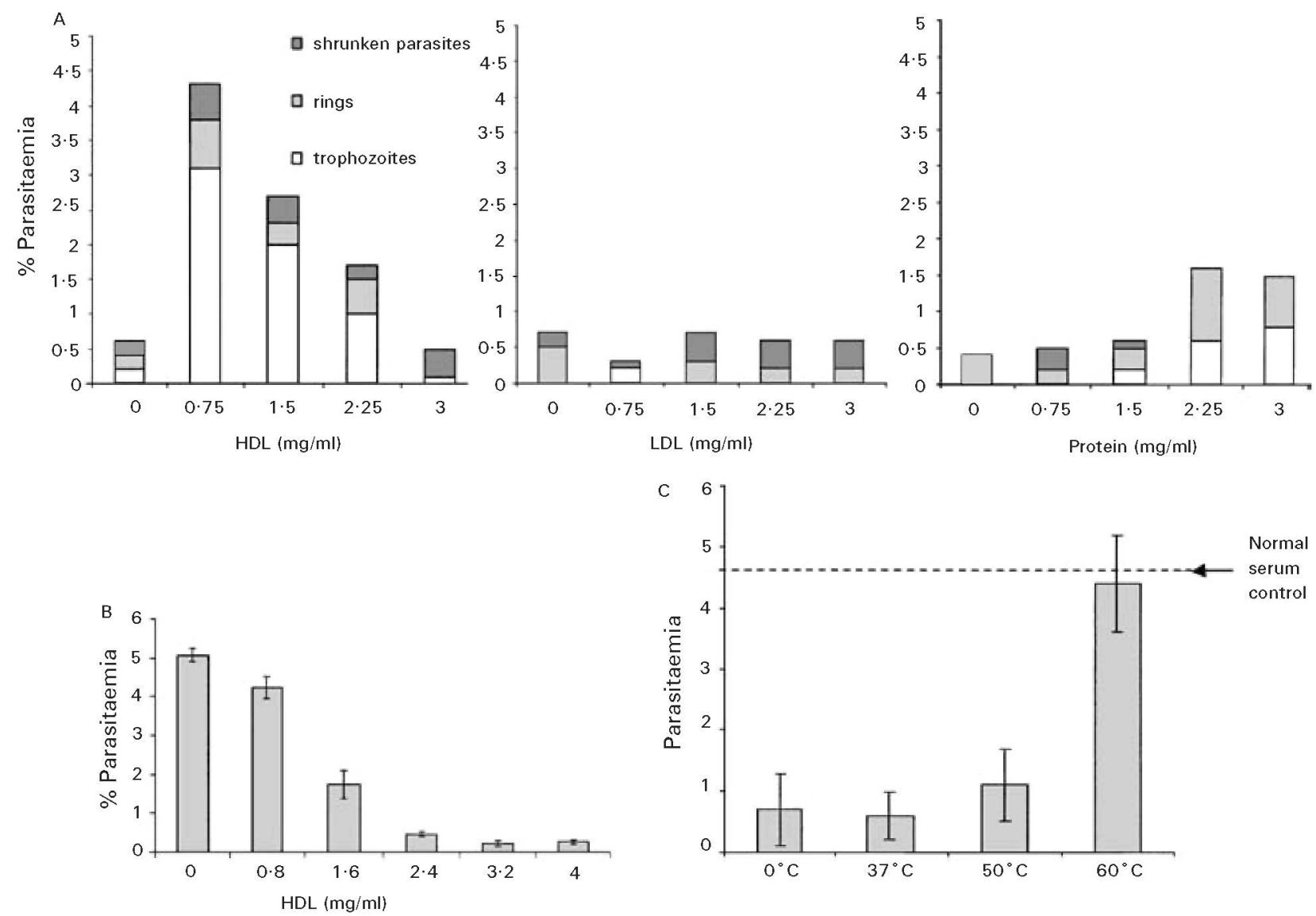

Fig. 1. Effects of HDL on parasite replication. (A) Late ring-stage parasites at a parasitaemia of $1 \%$ were cultured in RPMI alone, with various concentrations of HDL, LDL or protein (expressed as $\mathrm{mg} / \mathrm{ml}$ of protein) for $72 \mathrm{~h}$, the medium being replaced daily. Percentage parasitaemia was determined by flow cytometry and parasite stage and health by light microscopy. HDL in the absence of serum reduced parasite re-invasion in a dose-dependent manner. (B) Late ring-stage parasites at a parasitaemia of $1 \%$ were cultured in $5 \%$ NHS with various concentrations of HDL (expressed as $\mathrm{mg} / \mathrm{ml}$ of protein) for $24 \mathrm{~h}$. Parasites were then maintained in $5 \%$ serum until re-invasion had occurred, at which time the percentage parasitaemia in each culture was determined by flow cytometry. HDL in the presence of serum reduced parasite re-invasion. (C) HDL was heat treated at 0,37 or $50{ }^{\circ} \mathrm{C}$ for $30 \mathrm{~min}$, then added to parasites at toxic concentration ( $3 \mathrm{mg} / \mathrm{ml}$ protein) for $24 \mathrm{~h}$ and parasitaemias determined after re-invasion. Toxicity was abrogated by treatment of $\mathrm{HDL}$ at $50^{\circ} \mathrm{C}$.

of protein reduced parasitaemia by $95 \%$ in the cycle after treatment. LDL and protein-rich fractions had no effect on parasite growth in the presence of $5 \%$ serum (data not shown). Data are presented in Fig. $1 \mathrm{~B}$ for passages of the recently-adapted isolate Muz 37 , although similar results were obtained for isolates 1776, Muz 106 and the long-term established isolate $3 \mathrm{D} 7$ (data not shown).

The toxic factor was found to be heat-sensitive. In cultures containing 5\% normal human serum, the toxic effect of $\mathrm{HDL}$ at $3 \mathrm{mg} / \mathrm{ml}$ was unaffected by prior heat treatment at 0,37 or $50^{\circ} \mathrm{C}$ for $30 \mathrm{~min}$, but its toxicity was completely destroyed by heating HDL to $60^{\circ} \mathrm{C}$ for $30 \mathrm{~min}$ (Fig. 1C). In fact, heat treatment rendered this previously toxic concentration of HDL $(3 \mathrm{mg} / \mathrm{ml})$ capable of supporting parasite maturation and re-invasion in a serum-free system (data not shown). Heat treatment of HDL at $70{ }^{\circ} \mathrm{C}$ caused the fraction to solidify. Heat-treatment of the protein-rich fraction at 37,50 and $60^{\circ} \mathrm{C}$ did not affect its ability to support parasite re-invasion in a serum-free system, although temperatures of 70,80 and $90^{\circ} \mathrm{C}$ reduced (but did not completely abrogate) the capability of this fraction to support re-invasion.

In order to determine which life-cycle stages were sensitive to the toxic effect of the HDL, this fraction was added to cultures at different times. The presence of HDL $(3.2 \mathrm{mg} / \mathrm{ml})$ in cultures between 12 and $42 \mathrm{~h}$ post-invasion (i.e. during trophozoite maturation) prevented parasite replication. When HDL was added to late schizonts ( $42-48 \mathrm{~h}$ post-invasion) and was present during schizont rupture and merozoite release (removed $6-12 \mathrm{~h}$ after re-invasion), there was no reduction in re-invasion and growth in the following cycle. This indicates that schizonts and free merozoites were not sensitive to the toxic effects of HDL (data not shown).

Further evidence of the sensitivity of trophozoites to HDL was determined by incorporation of ${ }^{3} \mathrm{H}$ hypoxanthine. Cultures treated with $2.0 \mathrm{mg} / \mathrm{ml}$ 


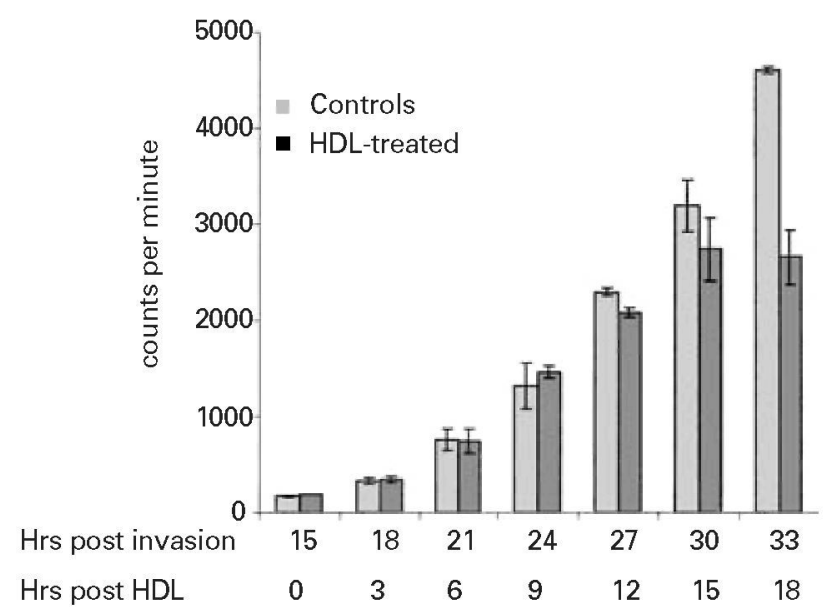

Fig. 2. Effects of HDL determined by tritiatedhypoxanthine uptake. Late ring-stage parasites at a parasitaemia of $1 \%$ were cultured in $5 \%$ NHS with ${ }^{3} \mathrm{H}$-hypoxanthine and various concentrations of HDL (expressed as $\mathrm{mg} / \mathrm{ml}$ protein) for $24 \mathrm{~h}$. Cells were then harvested and incorporation of radioactive hypoxanthine into parasite nucleic acid was determined by scintillation counting (expressed as counts per minute; CPM). The presence of HDL in the medium reduced nucleic acid synthesis in a dose-dependent fashion.

HDL protein at the late ring stage demonstrated approximately $70 \%$ inhibition of incorporation of ${ }^{3} \mathrm{H}$ hypoxanthine $24 \mathrm{~h}$ after addition of HDL (Fig. 2). Samples were taken every $3 \mathrm{~h}$ and the amount of labelled hypoxanthine incorporated into the parasites was determined. At $15 \mathrm{~h}$ after the addition of HDL (that is, approximately $30 \mathrm{~h}$ after erythrocyte invasion), a reduction in hypoxanthine uptake in the HDL treated parasites compared with controls was evident and this was obvious after $33 \mathrm{~h}$. Thus, the toxic effect of HDL occurred within a single growth cycle, confirming that trophozoite maturation was affected.

Light microscopical examination of smears was used to assess parasite growth and development when the HDL fraction was present in cultures during trophozoite maturation at a concentration of $1.44 \mathrm{mg} /$ $\mathrm{ml}$. Cultures were maintained for $30 \mathrm{~h}$, thin smears being prepared at various time-points and treated with Giemsa's stain (Fig. 3A). No obvious changes in parasite development were observed $12 \mathrm{~h}$ postHDL treatment. The detrimental effects of this treatment were observed after $18 \mathrm{~h}$ (i.e. in erythrocytes $30-36 \mathrm{~h}$ post-invasion). The parasitaemia was reduced by $50 \%$ suggesting that either there was some loss of parasites from erythrocytes, there was loss of infected erythrocytes or that parasites became undetectable within the erythrocytes. The remaining trophozoites were unhealthy compared with controls as determined by reduced size, irregular shape, increased staining density and presence of haemozoin outwith the food vacuole. The proportion of unhealthy trophozoites continued to increase 24 and
$30 \mathrm{~h}$ after addition of HDL. At $30 \mathrm{~h}$ the control parasites had formed mature schizonts. The treated parasites looked shrunken and densely coloured (Fig. $3 B$ ). Susceptibility to the toxic effect of HDL was thus detectable during trophozoite maturation.

The toxic effect of HDL on parasite development was also examined by electron microscopy $24 \mathrm{~h}$ after its addition to ring-stage cultures $(36-42 \mathrm{~h}$ after erythrocyte invasion) at sublethal concentration $(1.44 \mathrm{mg} / \mathrm{ml})$. In buffer-treated control samples, the majority (approximately 70\%) of infected erythrocytes contained parasites at the mid to late trophozoite stage with a few early and mature schizonts. A typical example of a segmenting schizont with merozoite buds is shown in Fig. 4A. Relatively few early stages (approximately 20\%) and dead parasites (approximately $7 \%$ ) were observed (Fig. 4C). The live parasites contained a large nucleus or multiple nuclei, rough endoplasmic reticulum, ribosomes, simple mitochondria and large food vacuoles, which contained a few loosely packed pigment crystals. In contrast, dead cells were characterized by the loss of membrane and organellar integrity. In addition, the infected erythrocytes exhibited numerous knobs (essential for adhesion) at the erythrocyte surface (Fig. 4A). In contrast to the control parasites, the HDL-treated samples contained low numbers of infected erythrocytes and these contained predominantly early trophozoite stages (approximately $60 \%$ ) (Fig. 4B) or dead parasites (Fig. 4B, insert). Very few late trophozoite stages (approximately $3 \%$ ) were observed (Fig. 4C). The parasites were small, containing a single nucleus and no large food vacuoles were observed, although a number contained pigment crystals in tight fitting vacuoles. The majority of infected erythrocytes possessed none or few knobs (Fig. 4B). The dead parasites were characterized by having either electron-lucent cytoplasm with disrupted membranes or were electron dense with loss of cytoplasmic detail, although clumps of pigment could be identified (Fig. 4B, insert). The number of dead parasites was related to the HDL concentration.

\section{DISCUSSION}

Our results show that at relatively low concentrations $(0.75 \mathrm{mg} / \mathrm{ml}$ protein) the HDL fraction of human serum is able to support parasite growth and reinvasion in a serum-free system. However, at higher concentrations $(2.4 \mathrm{mg} / \mathrm{ml}$ protein), the HDL is toxic to the parasite, causing grossly abnormal maturation and death of trophozoites. This coincides with the time (24-38 h post-invasion) when maximum uptake of labelled phosphatidylcholine from HDL occurs (Grellier et al. 1991). Differences in the results presented for light and electron microscopy and for flow cytometry are probably due to batch variation. Concentrations of HDL are given as $\mathrm{mg} / \mathrm{ml}$ 
A

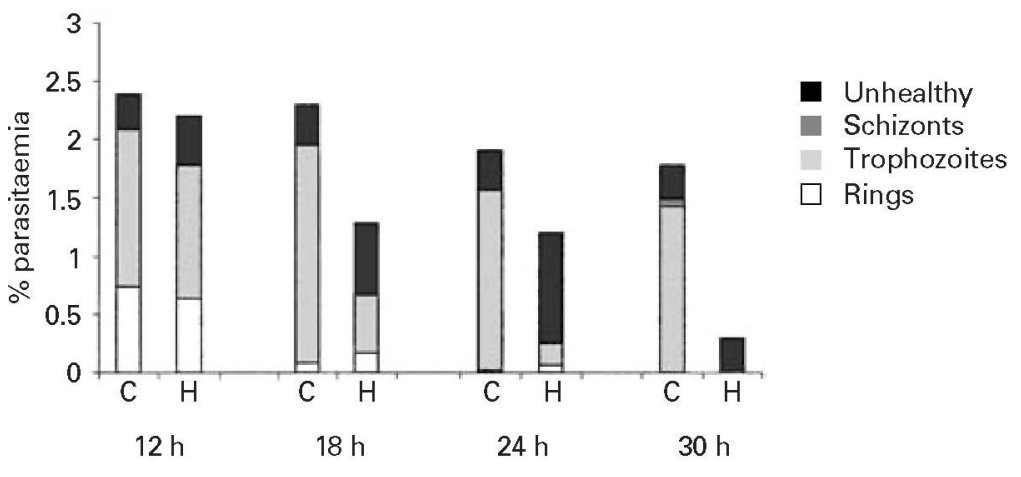

B
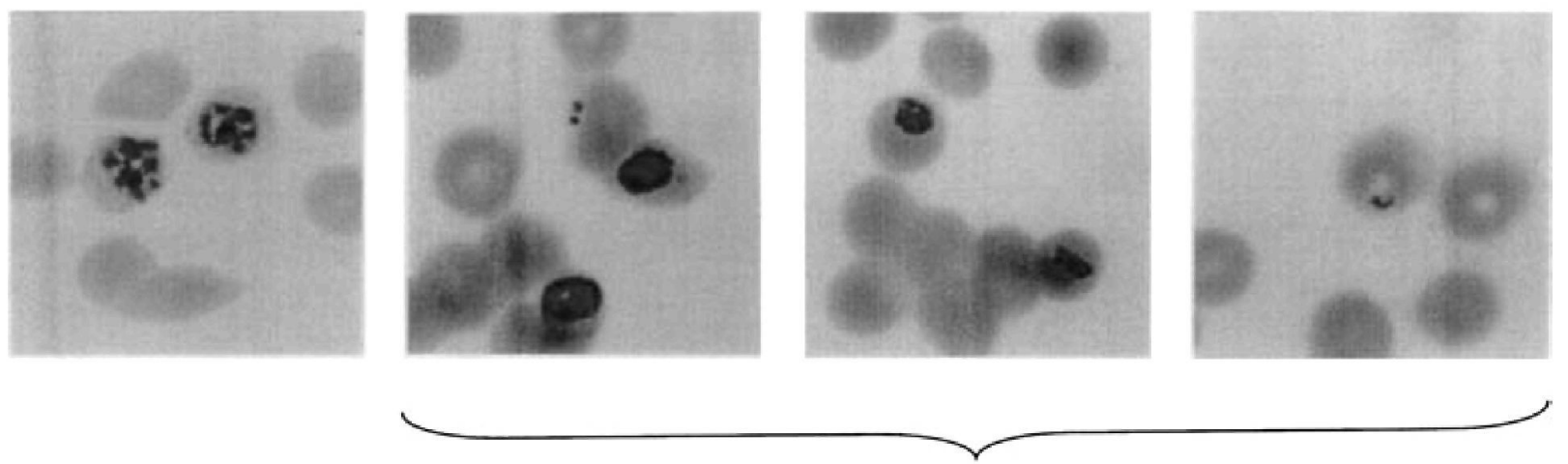

Fig. 3. Effects of HDL determined by light microscopy. (A) Late ring-stage parasites at a parasitaemia of $2 \%$ were cultured with HDL $(1.44 \mathrm{mg} / \mathrm{ml}$ protein) or with phosphate buffer (controls). Parasitaemia, parasite stage and health were then assessed by light microscopy at various time-points from 12 to $30 \mathrm{~h}$ after addition of HDL. C, control parasites;

H, HDL-treated parasites. Unhealthy parasites were shrunken, mishapen and/or had haemozoin pigment which did not appear to be in a single food vacuole. (B) Photographs from $30 \mathrm{~h}$ : control parasites had formed mature schizonts whereas treated parasites look shrunken and densely coloured.

of total protein, however, there may be individual variation in the active components within HDL.

The toxic effect of HDL was destroyed by heating at $60^{\circ} \mathrm{C}$ for $30 \mathrm{~min}$, and in fact, HDL treated thus was then able to support parasite growth in serumfree medium. This would suggest that the parasitebeneficial and parasite-toxic effects are mediated by different components within the HDL fraction. The protein-rich fraction of human serum was also shown to support parasite growth, although to a lesser extent than the HDL fraction in these experiments.

The requirements for parasite growth in vitro have been investigated by others. The need for phospholipid uptake was suggested by Grellier et al. (1991) who found that human HDL could support parasite growth in the absence of serum. Radioactive and fluorescence-labelling of phosphatidylcholine (PC) suggested that $P$. falciparum parasites take up phospholipid in a stage-specific manner (Grellier et al. 1991). Others have shown that trophozoites possess alternative transport pathways for the direct acquisition of intact phospholipid from the extraerythrocytic medium. For example, in uninfected erythrocytes $\mathrm{PC}$ remains within the outer leaflet of the erythrocyte membrane, whereas in infected cells $\mathrm{PC}$ is translocated across the erythrocyte membrane and thence to the parasite; a process which is energydependent and protein-mediated. In addition, a putative phosphatidylethanolamine transfer protein has been cloned.

Recent findings, however, would suggest that the Plasmodium genome contains genes encoding enzymes of phospholipid metabolism, allowing de novo synthesis of PC via the Kennedy pathway and necessitating only the uptake of the small choline molecule (reviewed by Vial et al. 2003). Biosynthetic pathways also exist for phosphatidyl serine and from these basic phospholipids, others can be synthesized (Vial et al. 2003). In addition, the genome of $P$. falciparum contains genes similar to those of type II fatty acid synthesis pathways. The protein products of these genes are located within the apicoplast and allow for the production of fatty acids, some of which are unique to the parasite (Vial et al. 2003). Thus the parasite may be able to meet many of its lipid requirements from its own biosynthetic pathways, although some extracellular lipids are necessary for 

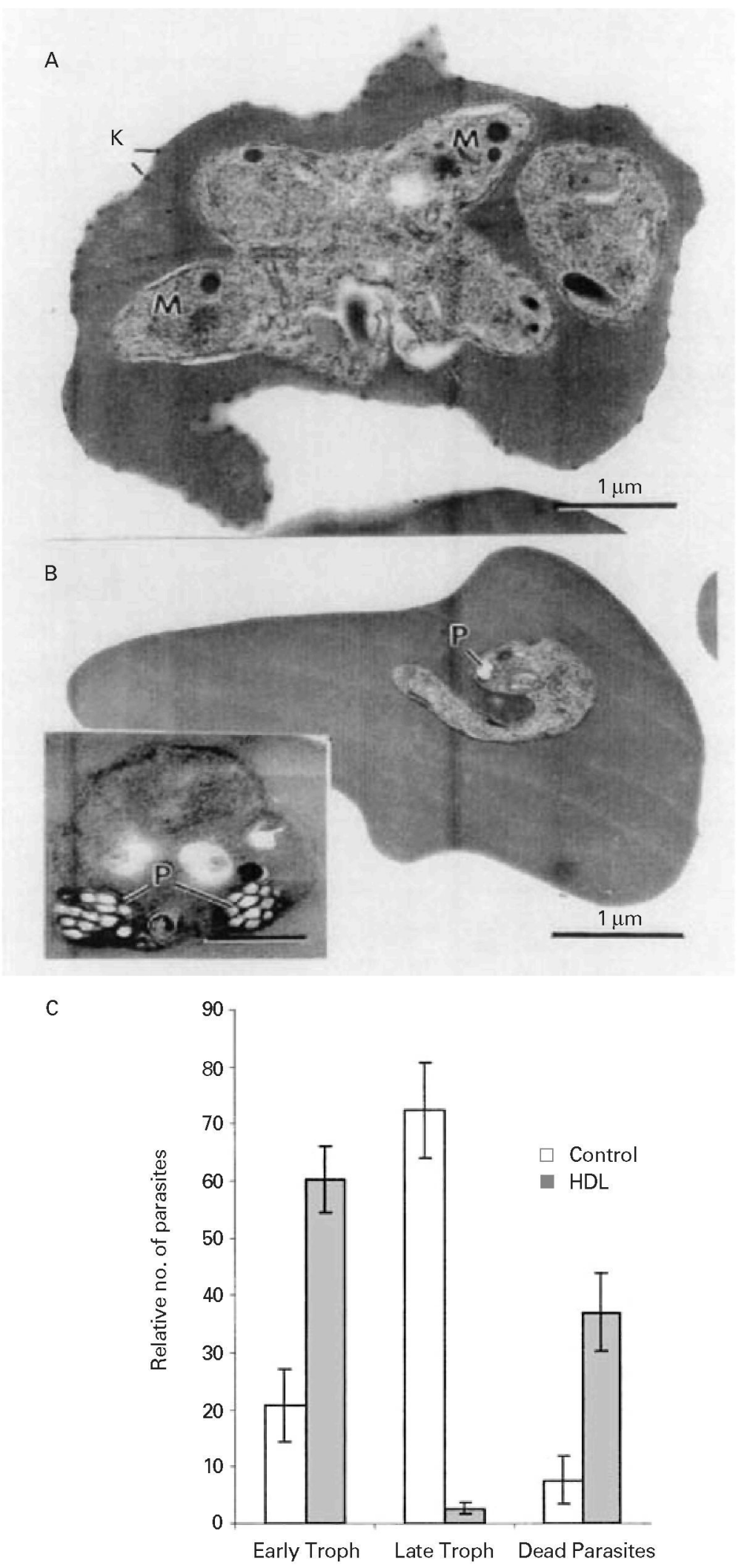

Fig. 4. Effects of HDL determined by electron microscopy. (A) Electron micrograph through an infected erythrocyte containing a schizont with developing merozoites (M) from the control sample at 24 h post-treatment. K, knob. (B) Section through an infected erythrocyte from a sample $30 \mathrm{~h}$ post-treatment with HDL in which an intact early trophozoite is present which contains a few pigment crystals $(P)$. Note the absence of knobs at the erythrocyte surface. The haemozoin has fallen out of the section leaving holes. (B insert) Detail of part of an infected erythrocyte from the HDL-treated sample showing a degenerate trophozoite which is recognizable by the presence of clumps of pigment crystals (P). (C) Graph showing the relative numbers of early trophozoites, late trophozoites and dead parasites in 100 infected erythrocytes from the control and treated groups at $24 \mathrm{~h}$ post-treatment, as determined by electron microscopy. 
in vitro growth. Mitamura et al. (2000) have shown that parasites can be maintained in serum-free medium supplemented with only bovine serum albumin and a pair of fatty acids; one saturated and one unsaturated, palmitic and oleic acids being the best combination. Albumin is a lipophilic protein which acts as a lipid carrier and is found in both HDL and protein fractions. This may explain why the proteinrich fraction of serum can support parasite growth in our system. The mechanism by which the parasite could acquire fatty acids from albumin is not known. It has been suggested that albumin is taken up by the parasite since biotinylated and iodinated albumin was detected in the parasite pellet following saponin lysis (Tahir, Malhotra \& Chauhan, 2003). However, whilst we have been able to obtain similar results using biotinylated albumin, FITC-labelled albumin was found to be bound only to parasites within damaged or ghosted erythrocytes (unpublished observations).

The results presented here confirm that both the HDL and protein-rich fractions of serum support parasite growth and re-invasion and this may be due to uptake of lipids from different components present within the two fractions or due to albumin present in both fractions. It is possible that both apolipoprotein A-I and albumin act as carrier molecules for transfer of lipid to the parasite, parasite-derived docking proteins allowing interaction between erythrocyte surface and the extracellular medium.

The toxic effect of HDL would seem to reside solely within the HDL fraction and to be distinct from the parasite-beneficial effects of HDL. The toxic component may be a heat-sensitive protein component of HDL and future work will concentrate on identifying the nature of this molecule. The catastrophic effects on the parasites growth and morphology make it difficult to speculate as to the action of the toxic moiety. Given that it is found within the HDL fraction, it is possible that it may in some way interfere with the uptake of lipid by the parasite. Fitch, Chen \& Cai (2003) have shown that linoleic acid may be necessary for the dimerization of ferriprotoporphyrin IX, the initial step in the production of haemozoin. In HDL-treated parasites the production of haemozoin would seem to have been disordered since no large food vacuoles were observed and, although pigment crystals were visible in some parasites, they were contained in abnormal tightfitting vacuoles. Our further investigations will try to define the identity and mechanism of action of the toxic component of HDL.

Professor Hajduk was supported by NIH. Professor Day was supported by a Research Leave Fellowship from The Wellcome Trust. Dr Imrie and Ms Carter were supported by Programme Grant funding awarded to Professor Day from The Wellcome Trust. Dr Ferguson was supported by an equipment grant from The Wellcome Trust. Professors
Hajduk and Day wish to acknowledge the scientific environment of the MBL campus at Woods Hole for the facilitation of this collaboration.

\section{REFERENCES}

BRUCE, M. C. \& DAY, K. P. (2002). Cross-species regulation of malaria parasitaemia in the human host. Current Opinion in Microbiology 5, 431-437.

DAY, K. P., Karamalis, F., THOMPSON, J., BaRnes, D. A., PETERSON, C., BROWN, H., BROWN, G. V. \& KEMP, D. J. (1993). Genes necessary for expression of a virulence determinant and for transmission of Plasmodium falciparum are located on a 0.3 Megabase region of chromosome 9. Proceedings of the National Academy of Sciences, USA 90, 8292-8296.

desjardins, R. E., CANFIEld, C. J., haynes, J. D. \& Chulay, J. D. (1979). Quantitative assessment of antimalarial activity in vitro by a semiautomated microdilution technique. Antimicrobial Agents and Chemotherapy 16, $710-718$.

FITCH, C. D., CHEN, Y. F. \& CAI, G. Z. (2003). Chloroquineinduced masking of a lipid that promotes ferriprotoporphyrin IX dimerization in malaria. Yournal of Biological Chemistry 278, 22596-22599.

FREEMAN, R. R. \& HOLDER, A. A. (1983). Light microscope morphology of Plasmodium falciparum during a synchronized growth cycle in vitro. Annals of Tropical Medicine and Parasitology 77, 95-96.

GRELLIER, P., RIGOMIER, D., CLAVEY, V., FRUCHART, J. C. \& SCHREVEL, J. (1991). Lipid traffic between high density lipoproteins and Plasmodium falciparum infected red blood cells. Yournal of Cell Biology 112, 267-277.

HAJDUK, S. L., MOORE, D. R., VASUDEVACHARYA, J., SIQUEIRA, H., TORRI, A. F., TYTLER, E. M. \& ESKO, J. D. (1989). Lysis of Trypanosoma brucei by a toxic subspecies of human high density lipoprotein. Fournal of Biological Chemistry 264, 5210-5217.

HALDAR, K. (1992). Lipid transport in Plasmodium. Infectious Agents of Disease 1, 254-262.

HALDAR, K., DEAMORIM, A. F. \& CROSS, G.A. M. (1989). Transport of fluorescent phospholipid analogs from the erythrocyte-membrane to the parasite in Plasmodium falciparum-infected cells. Fournal of Cell Biology 108, 2183-2192.

KWIATKowski, D. \& NOWAK, M. (1991). Periodic and chaotic host-parasite interactions in human malaria. Proceedings of the National Academy of Sciences, USA $\mathbf{8 8}$, 5111-5113.

LAMBros, C. \& VANDERBURG, J. P. (1979). Synchronization of Plasmodium falciparum erythrocytic stages in culture. Fournal of Parasitology 65, 113-139.

MITAMURA, T., HANADA, K., KO-MITAMURA, E. P., NISHIJIMA, M. \& HORII, T. (2000). Serum factors governing intraerythrocytic development and cell cycle progression of Plasmodium falciparum. Parasitology International 49, 219-229.

PASVOL, G., WILSON, R. J. M., SMALLEY, M. E. \& BROWN, J. (1978). Separation of viable schizont-infected red cells of Plasmodium falciparum from human blood. Annals of Tropical Medicine and Parasitology 72, 87-88.

PIPER, K. P., ROBERTS, D. J. \& DAY, K. P. (1999). Plasmodium falciparum: analysis of the antibody specificity to the surface of the trophozoite-infected erythrocyte. Experimental Parasitology 91, 161-169. 
TAHIR, A. E., MALHOTRA, P. \& CHAUHAN, v.s. (2003). Uptake of proteins and degradation of human serum albumin by Plasmodium falciparum-infected human erythrocytes. Malaria fournal 2, 11.

TRAGER, W. \& JENSON, J. B. (1976). Human

malaria parasites in continuous culture. Science $193,674-675$.
TROTTEIn, F. \& COWMAN, A. F. (1995). The primary structure of a putative phosphatidylethanolaminebinding protein from Plasmodium falciparum. Molecular and Biochemical Parasitology 70, 235-239.

VIAL, H. J., ELDIN, P., TIELENS, A. G. \& VAN HELLEMOND, J. J. (2003). Phospholipids in parasitic protozoa. Molecular and Biochemical Parasitology 126, 143-154. 